\title{
Effect of repeated restraint stress on memory in different tasks
}

G.D. Gamaro, M.B. Michalowski,

D.H. Catelli,

M.H. Xavier and

C. Dalmaz
Departamento de Bioquímica, Instituto de Ciências Básicas da Saúde, Universidade Federal do Rio Grande do Sul, Porto Alegre, RS, Brasil

\section{Correspondence \\ G.D. Gamaro \\ Departamento de Bioquímica ICBS, UFRGS \\ R. Ramiro Barcelos, 2600 \\ (Anexo) Lab. 32 \\ 90035-003 Porto Alegre, RS \\ Brasil \\ Fax: + 55-51-316-5535 \\ E-mail: gamaro@vortex.ufrgs.br \\ Research supported by PRO NEX, \\ FAPERGS and CNPq.}

Received January 22, 1998

Accepted November 25, 1998

\section{Abstract}

The present study investigated the effect of repeated stress applied to female rats on memory evaluated by three behavioral tasks: two-way shuttle avoidance, inhibitory avoidance and habituation to an open field. Repeated stress had different effects on rat behavior when different tasks were considered. In the two-way active avoidance test the stressed animals presented memory of the task, but their memory scores were impaired when compared to all other groups. In the habituation to the open field, only the control group showed a significant difference in the number of rearings between training and testing sessions, which is interpreted as an adequate memory of the task. In the handled and chronically stressed animals, on the other hand, no memory was observed, suggesting that even a very mild repeated stress would be enough to alter habituation to this task. The performance in the inhibitory avoidance task presented no significant differences between groups. The findings suggest that repeated restraint stress might induce cognitive impairments that are dependent on the task and on stress intensity.

\section{Introduction}

Stress response is an integral part of an adaptive biological system. It is well known that in response to stressful stimuli many hormones and neurotransmitters are released in order to help the organism to function in a dynamic and challenging environment (1). In this situation, adrenomedullary epinephrine is released and the hypothalamic-pituitary-adrenocortical (HPA) axis is activated, releasing hormones such as $\mathrm{CRH}, \mathrm{ACTH}$ and glucocorticoids (2). In addition, it is well recognized that several hormones re- leased during stress can influence memory storage (3-5). For example, epinephrine released or administrated shortly after a given training task modulates memory processes related to that experience $(3,4,6)$. As is the case for other stress-related hormones like ACTH and vasopressin, epinephrine has an inverted U-shaped dose-response curve: low doses facilitate memory while high doses impair retention $(3,4)$. Moreover, many studies have provided evidence that glucocorticoids regulate learning and memory (5,710). It has also been shown that stress impairs hippocampal long-term potentiation 
(LTP) $(11,12)$, a long-lasting increase in synaptic excitability that might be involved in the mechanism of memory storage (13$15)$.

Concerning the effects of chronic stress, evidence suggests that prolonged glucocorticoid secretion can have deleterious consequences, including damage to the hippocampus, a target tissue for glucocorticoids (GCs) rich in corticosteroid receptors and with marked sensitivity to GCs (16-18). The hippocampus is a critical site for memory $(11,13,19)$, and the loss of hippocampal neurons appears to be associated with the emergence of cognitive deficits in aged rats (16). On the other hand, chronically stressed animals do not experience all the hormonal consequences that animals exposed to a single stress episode do $(20,21)$, and it was suggested that previous exposure to chronic stress modified behavior in a novel stress situation $(22,23)$. Therefore, it seems reasonable that a previous history of repeated stress would modify behavior in a novel situation and since stress hormones can alter memory storage, a repeated stress regime could modify memory.

The present study investigated the effect of repeated stress on memory of adult female rats. Since different tasks used to evaluate memory involve different levels of stress, we assessed behavior of animals using three different tasks: two involving avoidance of a stimulus, and one involving habituation to a novel environment.

\section{Material and Methods}

\section{Subjects}

Seventy-one female adult Wistar rats (60 days old at the beginning of treatment) from our breeding stock were used. They were housed in groups of 6-8 animals per cage and kept under a normal 12-h dark/light cycle with food and water ad libitum.

\section{Stress model}

Animals were divided into three groups: stressed, handled and control. Restraint was obtained by placing the animal in a $25 \times 7$ $\mathrm{cm}$ plastic bottle, adjusting it with tape on the outside so that the animal was unable to move. There was a $1-\mathrm{cm}$ hole at one end for breathing. Animals were stressed $1 \mathrm{~h} /$ day, 5 days a week for 40 days (24). The immobilization procedure was performed between 10:00 and 12:00 $\mathrm{h}$ and the behavioral tasks between 14:00 and 16:00 h. In the handled group, animals were manipulated for 2-3 min, but were not submitted to restraint. Control animals were maintained in their home cages untouched. The stress was maintained during the behavioral task period.

\section{Behavioral procedures}

Habituation to the open field. A $50-\mathrm{cm}$ high, $40 \times 60-\mathrm{cm}$ open field made of brown plywood with a frontal glass wall was used (25). The floor was subdivided with white lines into 12 equal 13.3 - by $15.0-\mathrm{cm}$ rectangles. Both in the training and in the test session, the animals were gently placed facing the left corner and allowed to explore the arena for $5 \mathrm{~min}$. The performance of rearings, line crossings, and latency to the first crossing were counted in both sessions. The difference in the number of rearings between the test and the training trials was used as the measure of retention.

Step-down inhibitory avoidance. The animals were trained and tested for the one-way step-down inhibitory task using a 50 x $25 \mathrm{x}$ 25 -cm plywood box with a glass-wall front and a floor consisting of 1-mm bronze bars spaced $10 \mathrm{~mm}$ apart (25). The left end of the grid was covered with a $5-\mathrm{cm}$ high, $25-\mathrm{cm}$ wide, and 7.5-cm long wood platform. During the training trial, the animals were gently held by the body and lowered onto the platform with their noses pointing to the left 
corner, at which point a timer was activated. The timer measured the latency to step down (i.e., placing all four paws on the grid) at which point an intermittent footshock (0.3 $\mathrm{mA}, 60 \mathrm{~Hz}$ ) was delivered until the animal climbed back onto the platform. In the test session, the animals were again placed on the platform. No footshock was given in the testing session. A 300-s ceiling was imposed on testing session latency measurements; latencies $\geq 300 \mathrm{~s}$ were counted as $300 \mathrm{~s}$. Differences in testing-training session latencies were used as retention scores.

Two-way active avoidance. The animals were trained and tested in a two-way active avoidance task in an automatic $50 \times 25 \times 25$ $\mathrm{cm}$ opaque acrylic shuttle-box whose floor was a grid of 1-mm diameter bronze bars spaced $10 \mathrm{~mm}$ apart (25). Both the training and the test sessions consisted of 30 tonefootshock trials, preceded by 3-min free exploration of the shuttle-box, with no stimulation. In each session, the intertrial interval varied at random between 10 and $50 \mathrm{~s}$. Each 7 -s tone was immediately followed by a 0.5 $\mathrm{mA}$ footshock delivered until the animals crossed the midline. The shock was omitted if the animals crossed to the opposite side of the grid during the tone (avoidance response). The difference in the avoidance responses between the test and the training trials was used as the measure of retention (25).

\section{Statistical analysis}

Parametric data are reported as mean \pm SEM and were analyzed by one-way ANOVA or by repeated measures ANOVA, followed by the Student-Newman-Keuls test when indicated. Comparisons between training and test sessions were made by the Student paired $t$-test. Non-parametric data (i.e., latency to step-down from the platform in the test session of the inhibitory avoidance task) are reported as median (interquartile range) and were analyzed by the Kruskal-Wallis test, followed by the multiple comparison test based on Kruskal-Wallis scores, when indicated.

\section{Results}

\section{Effect of repeated stress on the open field task}

There was no significant difference in training performance between groups in the habituation to the open field, when considering the number of rearings (one-way ANOVA; $P>0.05$ ). The control group presented a significant difference between training and test sessions (Student paired $t$-test; $\mathrm{P}<0.01$ ), which was interpreted as an adequate memory of the task (Figure 1). On the other hand, no difference was found in handled and chronically stressed animals (Student paired $t$-test; $\mathrm{P}>0.05$ ).

The number of crossings in both sessions was also analyzed. No differences from control values were found in this parameter (control group: $76.4 \pm 4.6$ for training session and $72.0 \pm 4.1$ for test session; handled group: $80.7 \pm 5.8$ for training session and $85.2 \pm 5.6$ for test session; stressed group: $66.6 \pm 7.0$ for training session and $66.1 \pm 8.5$

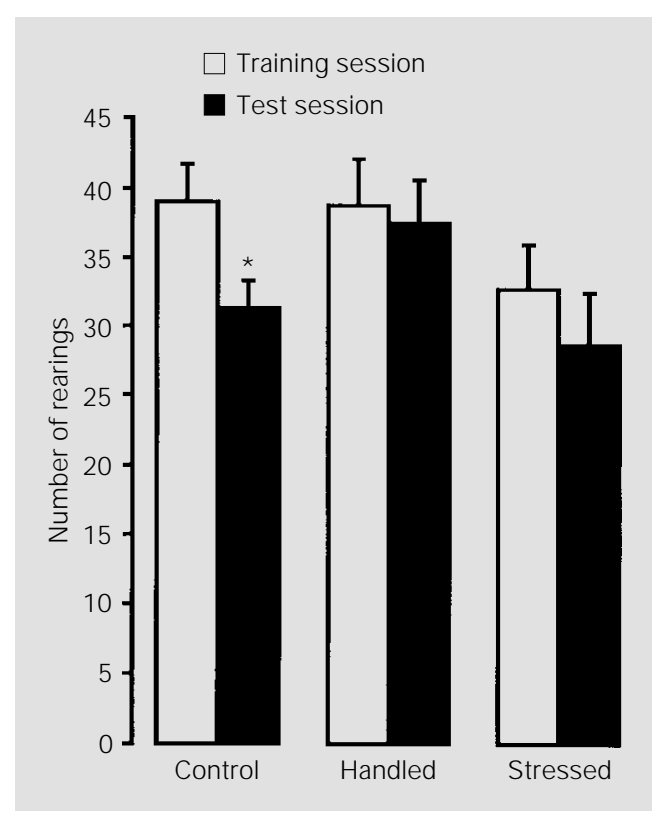

Figure 1 - Effect of chronic restraint stress on performance in an open field task. Data are reported as mean \pm SEM $(\mathrm{N}=23$ 24 animals/group) number of rearings. There were no significant differences between groups (one-way ANOVA, P>0.05). $* P<0.01$ compared to the training session (paired Student ttest). 
Figure 2 - Effect of chronic restraint stress on performance in the test session of a step-down inhibitory avoidance task. Data are reported as median (interquartile range) of the latency to step-down ( $\mathrm{N}=10-11$ animals/ group). There was no difference between groups (multiple comparisons based on the KruskalWallis test; $\mathrm{P}>0.05$ ). for test session) or in the latency to the first crossing (both ANOVA, with $\mathrm{P}>0.05$ ).

\section{Effect of stress on the inhibitory avoidance task}

In the step-down inhibitory avoidance task, there was no significant difference between groups in the training session (oneway ANOVA; $\mathrm{P}>0.05$ ). In the test session, although the chronically stressed group presented an increased latency to step-down from the platform, there was no significant difference in performance between groups

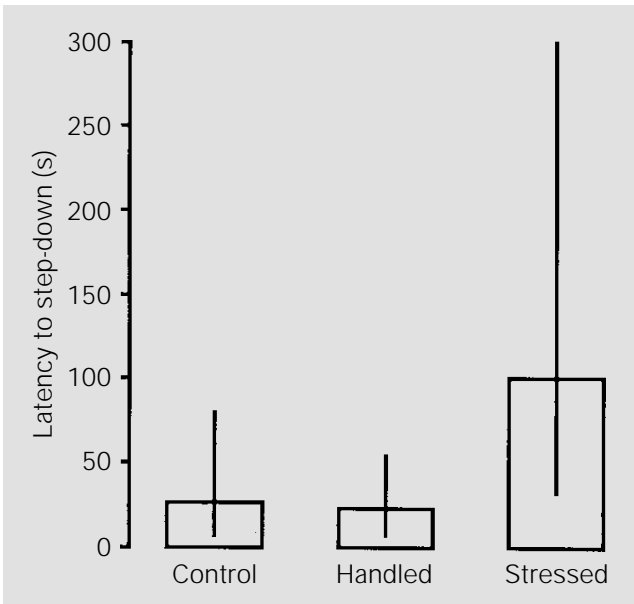

Figure 3 - Effect of chronic restraint stress on performance in a two-way active avoidance task. Data are reported as mean \pm SEM number of active avoidances in the training and testing sessions, and as the difference between these sessions (delta) ( $\mathrm{N}=15-16$ animals/group) $* \mathrm{P}<0.05$ compared to all other groups (Student-Newman-Keuls test).

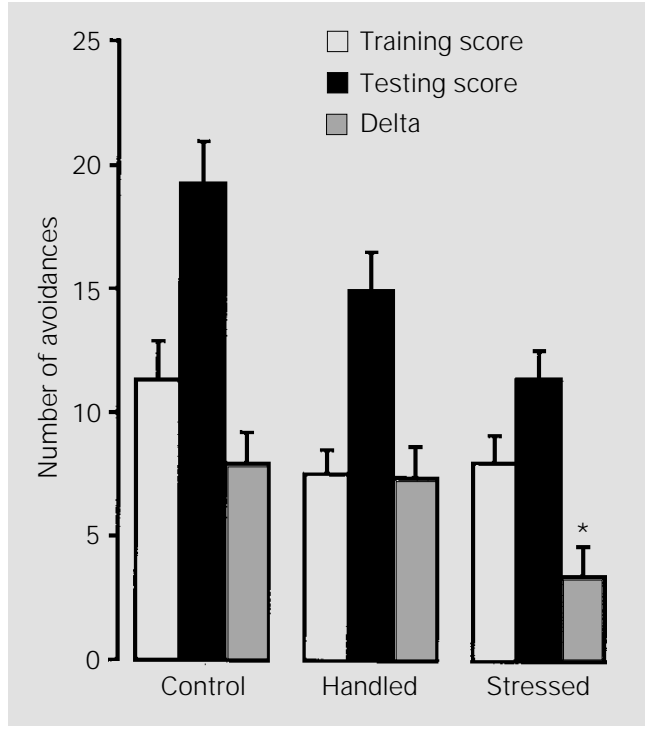

(multiple comparisons based on the KruskalWallis test; $\mathrm{P}>0.05$ ) (Figure 2).

\section{Effects of repeated stress on two-way active avoidance}

In the two-way active avoidance task, there was no significant difference in training performance between groups (one-way ANOVA; $\mathrm{P}>0.05$ ). Control and handled animals showed better retention scores (testtraining number of avoidances) when compared to chronically stressed animals (oneway ANOVA, followed by the StudentNewman-Keuls test; $\mathrm{P}<0.05$ ) (Figure 3). Comparisons between training and test sessions showed significant differences for all groups (Student paired $t$-test; $\mathrm{P}<0.001$ for control and handled groups, and $\mathrm{P}<0.05$ for chronically restrained group). There were no differences in the number of intertrial crossings (i.e., crossings to the other side of the box not related to the stimulus).

\section{Discussion}

It has been well established that acute stress or the administration of hormones released by stressful experiences may alter memory of certain tasks $(3,4,6)$. Depending on the level of stress involved, this effect could be a facilitatory or an inhibitory one (3).

Several studies have suggested that exposure to glucocorticoids, hormones released by the adrenal cortex during stress, may increase the vulnerability of hippocampal cells to certain insults that can damage hippocampal neurons $(17,26)$. The hippocampus plays important roles in cognition and neuroendocrine function $(13,19)$, and is known to be important for the consolidation of memories in different tasks, including the tasks studied in this report (27). It should be noted that while deleterious effects of excess glucocorticoid on the brain have been shown, there is little evidence indicating whether 
brain function itself is compromised in a situation of repeated stress.

The data reported here suggest that repeated stress has different effects on rat behavior when different tasks are considered. The behavioral studies revealed evidence of impairment that was dependent on the task and on the type of chronic stress used, since handling, that can be considered stressful for the animals, also affected performance in the open field task. In the inhibitory avoidance task, there was no significant increase in the latency to step-down, which is not due to an action on motor activity, because this repeated stress did not modify ambulation in a novel environment. The performance in the two-way active avoidance task was affected only in the repeatedly restrained animals, while in the open field task performance was affected in both the chronically restrained and handled groups, suggesting that even a very mild chronic stress would be enough to alter performance in this task. Our results with the open field task are similar to those obtained by Dachir et al. (9) in a previous study, using implanted corticosterone sustained-release pellets for 2 weeks. In that study, chronic corticosterone treatment induced habituation impairment that was reversed by treatment with nimodipine.

It should be noted that the effects of a chronic stress regime are not dependent on the level of stress associated with the memory task: exposure to the open field does not involve pain or a high level of stress, while in the inhibitory avoidance task the animals are exposed to one low intensity foot-shock, and in the two-way active avoidance they receive several foot-shocks.

It was previously observed that chronic stress may depress exploratory activity (22). In the present study, we observed an increased latency to step down in the inhibitory avoidance and a decreased number of crossings in the open field test, but neither effect was significant. It is important to consider that the stressed animals could present different levels of emotional reactivity interfering with memory. It has been shown that exposure to an inescapable shock leads to a deficit in escape behavior (28). In addition, animals submitted to a chronic variable stress regime show escape deficit in a shuttle-box task (29). Both stimuli, inescapable shock and chronic variable stress, are utilized in models of depression $(30,31)$. The repeated restraint stress used in the present study, however, is not considered a model of depression. Actually, previous work by Ely et al. (24) has shown that this type of repeated stress can induce a state of anxiety in rats. So, the evaluation of memory in other tasks is also desirable.

In the present work we used female rats to assess the effects of repeated restraint stress on memory. A sex difference in the response of the hypothalamus-pituitary-adrenal (HPA) axis to stress exists $(32,33)$, with females reacting more robustly than males $(32,34)$. It appears that testosterone can act to inhibit HPA function, whereas estrogen enhances it $(32,35)$. So it is possible that males would have different responses when submitted to this repeated stress.

The possibility of an adaptation of these animals to chronic stress should be considered, in such a way that this task would cause a different degree of stress in chronically stressed and control animals. Studies have demonstrated that prolonged exposure to different kinds of stress causes hyperresponsiveness of the hypothalamus-pituitary-adrenal axis to a new stimulus, although there is a desensitization of the relative responses of the pituitary ACTH to the primary stressor $(21,36)$. Other studies have shown behavioral effects of a single restraint stress that are not present after repeated restraint periods in males. Female rats, although less affected by a single restraint, failed to adapt over 5 daily restraint periods $(37,38)$.

In our study we used animals housed in groups. It has been shown in rats, pigs and lambs that stress responses are considerably 
more pronounced and persistent in animals deprived of possibilities of social contacts and that isolation can be considered another type of stress $(39,40)$.

These results led us to conclude that chronic exposure to stressors is capable of modifying memory. Chronic restraint stress causes changes in memory of specific tasks, and these effects are not related to the levels of stress associated with the task.

\section{References}

1. Ursin H \& Olff M (1993). The stress response. In: Stanford S \& Salmon P (Editors), Stress: From Synapse to Syndrome. Academic Press, London, 3-22.

2. Sapolsky RM (Editor) (1992). An introduction to the adrenocortical axis. In: Stress, the Aging Brain, and the Mechanisms of Neuron Death. Bradford, MIT Press, Cambridge, 11-27.

3. Gold PE \& Van Buskirk R (1978). Posttraining brain norepinephrine concentrations: correlation with retention performance of avoidance training and with peripheral epinephrine modulation of memory processing. Behavioral Biology, 23: 509-520.

4. Izquierdo I \& Dias RD (1983). Effect of $\mathrm{ACTH}$, epinephrine, ß-endorphin, naloxone, and of the combination of naloxone or ß-endorphin with ACTH or epinephrine on memory consolidation. Psychoneuroendocrinology, 8: 81-87.

5. Bohus B \& de Kloet ER (1981). Adrenal steroids and extinction behavior: Antagonism by progesterone, deoxycorticosterone and dexamethasone of a specific corticosterone effect. Life Sciences, 28: 433-440.

6. Gold PE \& Van Buskirk R (1975). Facilitation of time-dependent memory processes with posttrial epinephrine injections. Behavioral Biology, 13: 145-153.

7. Roozendaal $B$, Bohus $B$ \& McGaugh J L (1997). Dose-dependent suppression of adrenocortical activity with metyrapone: Effects on emotion and memory. Psychoneuroendocrinology, 21: 681-693.

8. Flood J F, Vidal D, Bennett EL, Orme AE, Vasquez S \& J anvik ME (1978). Memory facilitating and anti-amnesic effects of corticosteroids. Pharmacology, Biochemistry and Behavior, 8: 81-87.

9. Dachir S, Robinzon B, Grauer E \& Levy A (1995). Nimodipine counteracts corticosterone-induced habituation impairments. Neurobiology of Learning and Memory, 63: 241-245.

10. Venero C \& Sandi C (1997). Effects of NMDA and AMPA receptor antagonists on corticosterone facilitation of long-term memory in the chick. European J ournal of Neuroscience, 9: 1923-1928.

11. Foy MR, Stanton ME, Levine $S \&$ Thompson RF (1987). Behavioral stress impairs long-term potentiation in rodent hippocampus. Behavioral and Neural Biology, 48: 138-149.

12. Shors TJ , Foy MR, Levine $S \&$ Thompson RF (1990). Unpredictable and uncontrollable stress impairs neuronal plasticity in the rat hippocampus. Brain Research Bulletin, 24: 663-667.

13. Izquierdo I (1993). Long-term potentiation and mechanisms of memory. Drug Development Research, 30: 1-17.

14. Bliss TVP \& Collingridge GL (1993). A synaptic model of memory: Long-term potentiation in the hippocampus. Nature, 361: 31-39.

15. Izquierdo I \& Medina J H (1995). Correlation between the pharmacology of memory and the pharmacology of longterm potentiation. Neurobiology of Learning and Memory, 63: 17-29.

16. Issa AM, Rowe W, Gauthier $S \&$ Meaney MJ (1990). Hypothalamic-pituitary-adrenal activity in aged, cognitively impaired and cognitively unimpaired rats. J ournal of Neuroscience, 10: 3247-3254.

17. Sapolsky RM, Packan DR \& Vale WW (1988). Glucocorticoid toxicity in the hippocampus: in vitro demonstration. Brain Research, 453: 367-371.

18. Sapolsky RM (Editor) (1992). Glucocorticoids endanger hippocampal neurons. In: Stress, the Aging Brain, and the Mechanisms of Neuron Death. Bradford, MIT Press, Cambridge, 119-143.

19. J arrard LE (1993). On the role of the hippocampus in learning and memory in the rat. Behavioral and Neural Biology, 60: 926.

20. Hashiguchi $\mathrm{H}, \mathrm{Ye} \mathrm{HSH}, \mathrm{Morris} \mathrm{M} \&$ Alexander N (1997). Single and repeated environmental stress: effect on plasma oxytocin, corticosterone, catecholamines and behavior. Physiology and Behavior, 61: 731-736.
21. Tizabi Y \& Aguilera G (1992). Desensitization of the hypothalamic-pituitary-adrenal axis following prolonged administration of corticotropin-releasing hormone or vasopressin. Neuroendocrinology, 56: 611618.

22. Garcia-Marquez C \& Armario A (1987). Chronic stress depresses exploratory activity and behavioral performance in the forced swimming test without altering ACTH response to a novel acute stressor. Physiology and Behavior, 40: 33-38.

23. Cancela LM, Bregonzio $C \&$ Molina VA (1995). Anxiolytic-like effect induced by chronic stress is reversed by naloxone pretreatment. Brain Research Bulletin, 36: 209-213.

24. Ely DR, Dapper V, MarascaJ M, Correa J B, Gamaro GD, Xavier MH, Michalowski MB, Catelli D, Rosat R, Ferreira MBC \& Dalmaz $C$ (1997). Effect of restraint stress on feeding behavior of rats. Physiology and Behavior, 61: 395-398.

25. Gutierrez-Figueroa GP, Dalmaz C \& Izquierdo I (1997). Effects of entorhinal cortex lesions on memory in different tasks. Brazilian J ournal of Medical and Biological Research, 30: 769-774.

26. Sapolsky RM, Krey LC \& McEwen BS (1985). Prolonged glucocorticoid exposure reduces hippocampal neuron number: implications for aging. J ournal of Neuroscience, 5: 1222-1227.

27. Izquierdo I \& Medina J H (1993). Role of the amygdala, hippocampus and entorhinal cortex in memory consolidation and expression. Brazilian J ournal of Medical and Biological Research, 26: 573-589.

28. Anisman $\mathrm{H}$, de Catanzaro $\mathrm{D} \&$ Remington $\mathrm{G}$ (1978). Escape performance following exposure to inescapable shock: Deficits in motor response maintenance. J ournal of Experimental Psychology, Animal Behavior Processes, 4: 197-218.

29. Murua VS, Gomez RA, Andrea ME \& Molina V (1991). Shuttle-box deficits induced by chronic variable stress: Reversal by imipramine administration. Pharmacology, Biochemistry and Behavior, 38: 125- 
130.

30. Sherman $A D$, Allers $G L$, Petty $F$ \& Henn FA (1979). A neuropharmacologically-relevant animal model of depression. Neuropharmacology, 18: 891-893.

31. Willner P \& Muscat R (1991). Animal models for investigating the symptoms of depression and the mechanisms of action of antidepressant drugs. In: Olivier B, Mos J \& Slougen J L (Editors), Animal Models in Psychopharmacology. Birkhaeuser Verlag, Basel, 183-197.

32. Handa RJ , Burgess LH, KerrJ E \& O'Keefe J A (1994). Gonadal steroid hormone receptors and sex differences in the hypothalamo-pituitary-adrenal axis. Hormones and Behavior, 28: 464-476.

33. Gallucci WT, Baum A, Laue L, Rabin DS, Chrousos GP, Gold PW \& Kling MA (1993). Sex differences in sensitivity of the hypothalamic-pituitary-adrenal axis. Health Psychology, 12: 420-425.

34. Ehlers CL, Kaneko WM, Owens MJ \& Nemeroff CB (1993). Effects of gender and social isolation on electroencephalogram and neuroendocrine parameters in rats. Biological Psychiatry, 33: 358-366.

35. Viau V \& Meaney MJ (1996). The inhibitory effect of testosterone on hypothalamic-pituitary-adrenal responses to stress is mediated by the medial preoptic area. J ournal of Neuroscience, 16: 1866-1876.

36. Bhatnagar S \& Dallman M (1998). Neuroanatomical basis for facilitation of hypothalamic-pituitary-adrenal responses to a novel stressor after chronic stress. Neuroscience, 84: 1025-1039.

37. Kennett GA, Chaouloff $F$, Marcou $M \&$ Curzon $G$ (1986). Female rats are more vulnerable than males in an animal model of depression: the possible role of serotonin. Brain Research, 382: 416-421.

38. Haleem DJ , Kennett G \& Curzon G (1988). Adaptation of female rats to stress: shift to male pattern by inhibition of corticosterone synthesis. Brain Research, 458: 339-347.

39. Sanchez MM, Aguado F, SanchezToscano F \& Saphier D (1998). Neuroendocrine and immunocytochemical demonstrations of decreased hypothalamo-pituitary-adrenal axis responsiveness to restraint stress after long-term social isolation. Endocrinology, 139: 579-587.

40. J anssens CJ , Helmond FA \& Wiegant VM (1994). Increased cortisol response to exogenous adrenocorticotropic hormone in chronically stressed pigs: influence of housing conditions. J oumal of Animal Sciences, 72: 1771-1777. 